\title{
Ring-opening polymerization and plasticization of poly(L-lactic)acid by adding of glycerol-dioleate
}

\author{
Tibor Horváth $^{1}{ }^{10} \cdot$ Kálmán Marossy $^{1} \cdot$ Tamás J. Szabó $^{1}$
}

Received: 19 April 2020 / Accepted: 28 December 2020 / Published online: 15 February 2021

(c) The Author(s) 2021

\begin{abstract}
Poly-L-lactic acid (PLLA) has been produced by ring-opening polymerization method. During the polymerization processes different temperatures and process times have been applied to reach an optimum setup that was used to produce sample. The sample was measured by Fourier-transform infrared spectroscopy (FTIR), gel permeation chromatography (GPC) and differential scanning calorimetry (DSC) methods to identify the structure, molar mass and define the glass transition temperatures of product and obtain general information about the physical and chemical properties of material. Based on the results of measures, the material's crystallinity was also investigated. The plasticization of PLLA has been also investigated. During the experiments, previously produced material (PLLA synthesized by polycondensation) was plasticised by adding of glycerol-dioleate. The plasticized material was also measured by FTIR, GPC and DSC methods to check the basic physical and chemical parameters of the material. According to the results of the measurements that were found, by this approach, the glass transition temperature of PLLA was reduced by $7^{\circ} \mathrm{C}$ that indicated the glycerol-dioleate might act as a plasticizer for PLLA material without any deviation in the chemical structure of material.
\end{abstract}

Keywords PLLA · ROP · Glycerol-dioleate $\cdot$ Plasticizer $\cdot$ FTIR $\cdot$ GPC $\cdot$ DSC

\section{Introduction}

The polylactic acid (PLA) is widely used aliphatic polyester. Natural sourced and biodegradable, therefore, it has many fields of applications like medical (drug carrier, porous scaffolds for cellular applications, bone fixation devices, plates, pins, screws, and wires, coatings on metal impacts), food industrial field (packaging films, trays, blisters) or for other general purposes (commodity containers, mobile phone housing, floor mats) as it has been investigated by Babu et al. [1]. The new field of application is composites. Although the matrix material is PLA but the filler material can be organic or inorganic therefore this group can be divided for two main categories. In case of organic composites, especially bio-composites, the filler materials are organic/plantbased such as cassava and pineapple flours that was studied by Becker et al. [2]. Regarding the inorganic composites category inorganic materials are used as filler like calcium

Tibor Horváth

horvath.tibor7126@gmail.com

1 Institute of Ceramic and Polymer Engineering, University of Miskolc, Miskolc 3515, Hungary carbonate, barium-sulphate, mica, talc, zeolite or different formulations of basalt for biomedical composites which field has been widely studied [3, 4]. Special PLA types also developed and investigated such as flame resistance alternatives. To achieve the fire resistance and avoid the deterioration of mechanical properties of PLA special additives need to be used such as DOPO- $\mathrm{NH}_{2}$ that was tested and investigated by Wang et al. [5]. Among others, Bouapao et al. investigated the relationship between the lactic acid monomers and polymer alternatives. Found that, as the lactic acid is a chiral molecule and has two stereoisomers (Fig. 1), three different PLA types can be formed as poly(L-lactic)acid (PLLA) and poly(D-lactic)acid and poly(DL-lactic)acid (PDLLA). The isotactic and optically active PLLA and PDLA are mostly crystalline which highly depends on crystallization time and optimal crystallization temperature, and the properties and effects of filler material in case of composites [6-9]. The PDLLA is relatively atactic and optically inactive and its structure is amorphous [10].

To produce polylactic acid, two main polymerization types are used. With application of standard polycondensation, PLA with low molar mass can be synthesized. The problem of this polymerization type is the relative high 
<smiles>C[C@@H](O)C(=O)O</smiles>

D-lacic acid<smiles>C[C@@H](O)C(=O)O</smiles>

L-lacic acid
Fig. 1 Stereoisomers of lactic acid [11]

demand of process time. The other, more efficient polymerization is the ring-opening polymerization (ROP) (Fig. 2). Although this method is the most effective polymerization type for PLA but this process is much more complicated compared to the standard polycondensation as this process divided to three main steps that was also concluded by Lee and Bee [12].

The ROP method is a propagation process of cyclic monomers. The process can be initiated by ions, and therefore, anionic, cationic and radical ROPs mechanisms are classified [14]. In case of PLA, the cyclic monomer is the lactide that is the cyclic dimer of lactic acid. The controlled ROP induces specific and desirable physical and chemical properties for polymers that was widely discussed in work of Stridsberg et al. [15] .

By the ROP process - through polymerization of lactides-polymer with wider range of molecular mass could be produced by controlling the purity of lactide and synthesis conditions without adding chain coupling agent. Due to these facts, the ROP method is applied by some leader PLA producers like Cargill Dow (Minnetonka, MN, USA) and Shimadzu (Kyoto, Japan) [16].

Fig. 2 PLA synthesis route [13]
To achieve controlled molecular mass during the ringopening polymerization of the lactide, catalyst needs to be used. The catalyst type depends on the monomer and conditions of reactions. Different types of metal catalysts such as tin(II)2-ethylhexanoate or stannous octoate ( $\mathrm{Sn}(\mathrm{Oct}) 2)$ have been widely used as with application of these catalysts high reaction rates and high molecular mass can be realized. The types of possible catalysators have been studied by many occasions [17, 18].

Over the catalyst, the other key factor is the applied thermal condition. As the total polymerization process can be divided for main steps like dehydration, polymerization, degradation (lactide production) and ROP polymerization-each step has optimal temperature ranges that can guarantee the most effective result. However, the thermal circumstances depend on many factors like stereochemical purity of monomers, ratio of L, D isomers or water content and chemical ingredients of raw material. From the other hands, the requirements against the polymer, as well the expected efficiency of production can also impact on the process and its circumstances. The effect and importance of thermal condition of polymerization processes have been widely studied [19-22].

\section{Experimental}

\section{Materials}

During the experiments pure (general purity $>90 \%$; stereochemical purity of materials $>99 \%$ ) L-lactic acid was used. The raw material was purchased from Musashino Chemical Laboratory Ltd. During the ring-opening-polymerization<smiles>CC(O)C(=O)OC(C)C(=O)OC(C)C(=O)O</smiles>

LACTIC ACID OLIGOMERS<smiles>CC(O)C(=O)C(C)OC(C)C(=O)OC(C)C(=O)OC(C)(C)C(=O)C(C)O</smiles> 
process stannous octoate $\left(\mathrm{C}_{16} \mathrm{H}_{30} \mathrm{O}_{4} \mathrm{Sn}\right)$ as catalyst, for plasticizing, glycerol-dioleate $\left(\mathrm{C}_{32} \mathrm{H}_{72} \mathrm{O}_{5}, 536 \mathrm{~g} \mathrm{~mol}^{-1}\right)$ as plasticizer was used. Both materials were provided by the University of Miskolc. Regarding the plasticization experiment, previously prepared sample was used that was produced by standard polycondensation method.

\section{Methods}

During the ring-opening-polymerisation processes, HEIDOLPH Laborota 400 efficient with joined Vacuubrand ME $1 \mathrm{C}$ type vacuum pump was used. To achieve higher temperature level $\left(180-220^{\circ} \mathrm{C}\right)$, this complex equipment was combined with 1260 VELP Arex-6 Digital. All tools and equipment were provided by KISANALITIKA Kft.

The ROP process has been divided for the mentioned dehydration, polymerization, depolymerization and lactide polymerization phases. In case of firstly carried-out dehydration, $100 \mathrm{~mL}$ pure lactic acid was added to the reactor flask. To remove the water content of polylactic acid solution moderated temperature was chosen to use to minimize the vapourization loss of monomers.

$T_{\text {dehydration }}<T_{\text {boiling point of lactic acid }}\left({ }^{\circ} \mathrm{C}\right)$

The standard polymerization (polycondensation) phase was performed on various temperatures with various process times. The reaction mixture was stirred continuously (Fig. 3).

After an appropriate time, the temperature was gradually increased to higher temperature in order of formation of lactides and oligomers as products of depolymerisation process. The process temperature was chosen and kept under the critical decomposition temperature.

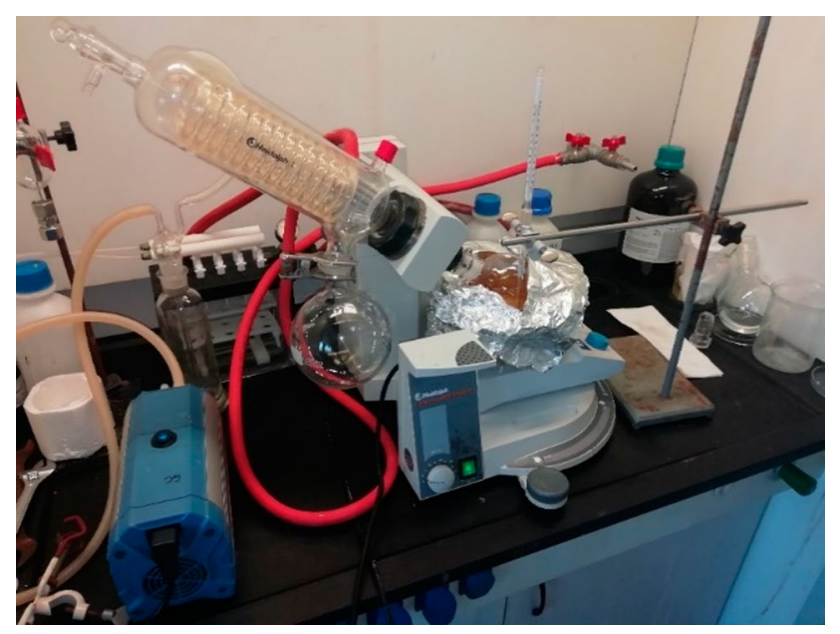

Fig. 3 HEIDOLPH Laborota 400 efficient with Vacuubrand ME 1C type vacuum pump and 1260 VELP Arex-6 Digital stirrer
$T_{\text {depolymerisation }}<T_{\text {decomposition }}\left({ }^{\circ} \mathrm{C}\right)$

The formatted lactides were continuously removed and collected (Fig. 4). Then, the produced lactides were dried on $40^{\circ} \mathrm{C}$ at $2 \mathrm{~h}$.

In the last step, the dried lactides and the proper amount of catalyst were added to a reaction flask then the whole system (with continuous stirring) was heated up to $140{ }^{\circ} \mathrm{C}$ for various time (Fig. 5), then the PLLA was dissolved in chloroform and precipitated by methanol then filtrated and dried. All ring-opening polymerization related parameters are shown in Table 1.

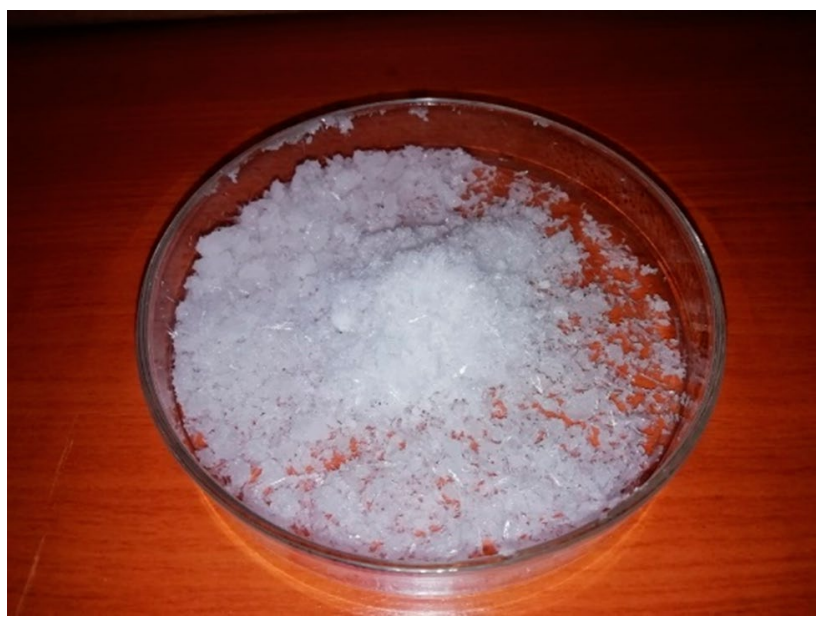

Fig. 4 Dried lactides produced by depolymerisation

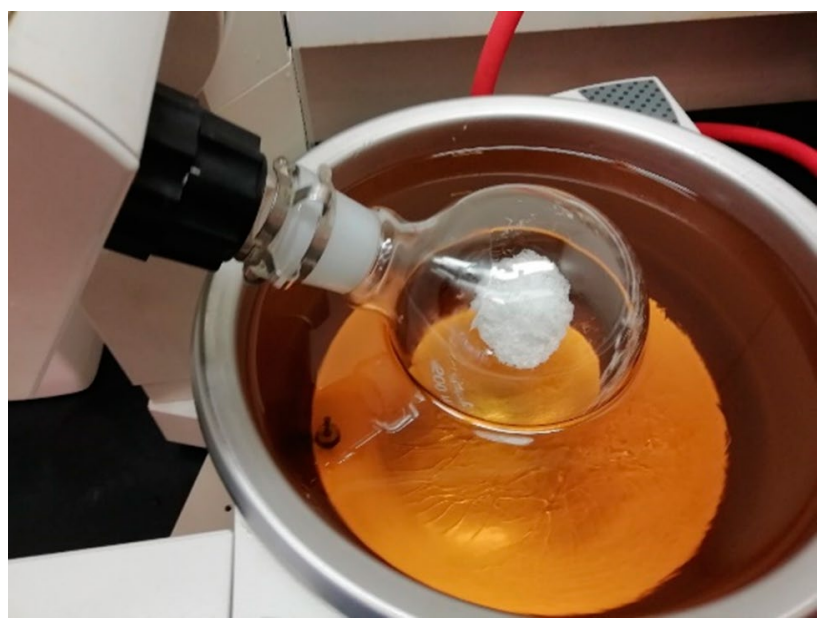

Fig. 5 Final step: ROP process 
Table 1 Various parameters of ROP method

\begin{tabular}{llll}
\hline Process phase & Time/h & Temperature $/{ }^{\circ} \mathrm{C}$ & Pressure $/$ mbar \\
\hline Dehydration & $0.5 / 1$ & $80 / 120$ & 100 \\
Polymerisation & $2-6$ & 160 & 100 \\
Depolymerisation & $12-18$ & $180-210$ & 100 \\
ROP & $4-8$ & 140 & 100 \\
\hline
\end{tabular}

In case of plasticization experiment, previously prepared PLLA (produced by polycondensation method) samples was used $6 \mathrm{~g}$ polymer and glycerol-dioleate as plasticizer with dosage of 2 mass $/ \%(0.12 \mathrm{~g}$ ) was added to a $250 \mathrm{~mL}$ rounded reaction flask. Under vacuum of $100 \mathrm{mb}$ and with continuous stirring, the mixture was heated up to $160{ }^{\circ} \mathrm{C}$ and held on this temperature for $1 \mathrm{~h}$.

During the follow-up measurements, the synthetized polymer samples have been analyzed by Fouriertransform infrared spectroscopy (FTIR) and differential scanning calorimetry (DSC) methods. In case of FTIR analysis, BRUKER Tensor 27 was used with ATR sample holder, and 64 scans were recorded with resolution of $4 \mathrm{~cm}^{-1}$. For DSC analysis, Setaram DSC131 Evo equipment was applied with $\mathrm{d} T / \mathrm{d} t=10^{\circ} \mathrm{C} \mathrm{min}^{-1}$ heating/cooling rates and with $0-190{ }^{\circ} \mathrm{C}$ heating range. Continuous nitrogen purge was ensured. The samples were prepared and dosed in $30 \mu \mathrm{L}$ aluminium pans. All the analytical equipment was provided by the Ceramics and Polymer Engineering Institute at the University of Miskolc.

The Mn and molecular mass distribution (Molecular Weight Distribution - MWD) of the polymers were measured by SEC-GPC in THF at $35^{\circ} \mathrm{C}, 0.5 \mathrm{~mL} \mathrm{~min}{ }^{-1}$ with a Waters chromatograph (e2695 Separation Module) equipped with an In-line Degasser, four gel columns (Styragel columns: HR 0.5, HR 1, HR 2, HR 4), and Waters 2414 Differential Refractometer detector. The Mn, Mw/ Mn values of the polymers were calculated from their chromatograms on the basis of a polystyrene calibration. The measurements were done by Department of Applied Chemistry at University of Debrecen.

\section{Results and discussion}

\section{Structure of materials determination by Fourier-transform infrared spectroscopy}

The basic structure of produced samples was analyzed and identified by FTIR method. The molecular structure of

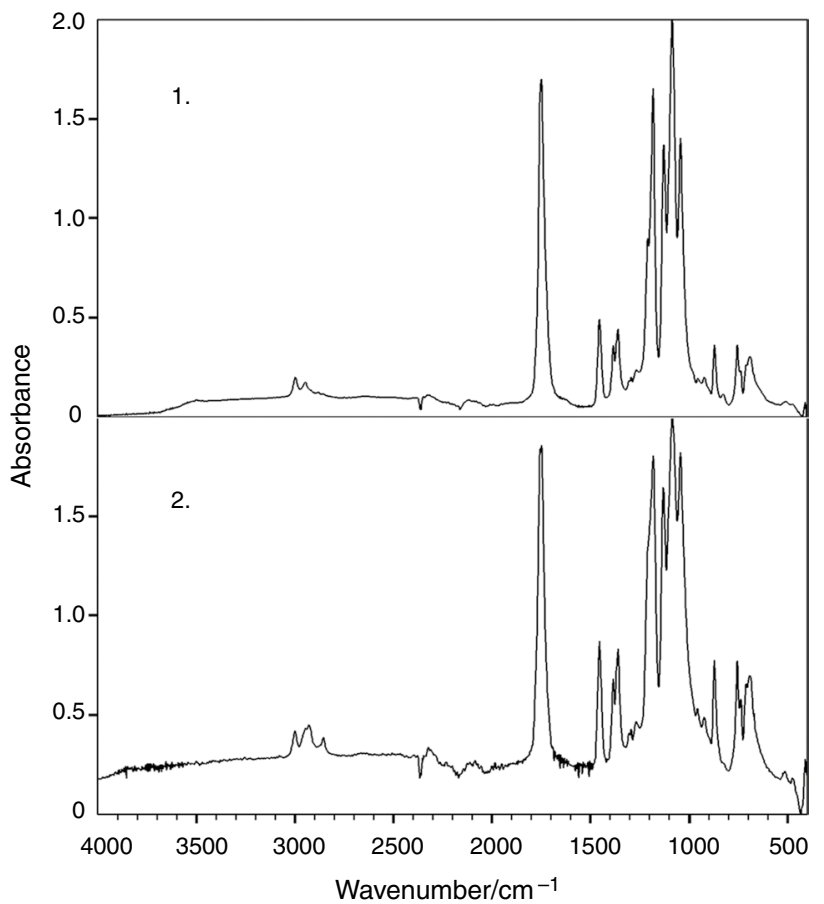

Fig. 6 FTIR spectra of 1. PLLA sample produced by ROP method; 2. plasticized version of PLLA produced by polycondensation method

PLLA sample that was produced ROP shown in Fig. 6/1, as the structure of plasticized PLLA shown in Fig. 6/2.

The resulted spectra of the measurements were analyzed and evaluated. According to the experienced equalities of results of measured samples and library standards [23] all analyzed polymers were found as polylactic acid. Both samples have been identified as PLA.

\section{Molar mass determination by gel permeation chromatography}

The GPC measurement resulted in Mw $6 \times 10^{3} \mathrm{~g} \mathrm{~mol}^{-1}$ molar mass for reference PLLA (which was used for plasticization experiment) that was previously produced by polycondensation method with molar mass distribution (Molecular Weight Distribution-MWD) of 1.51. Regarding the polymer sample which was produced by ROP technique, the $\mathrm{Mw}$ was found $3.8 \times 10^{3} \mathrm{~g} \mathrm{~mol}^{-1}$ with MWD 1.31. The volume of catalysator was higher than 1 mass $/ \%$ which is adversely affected the molar mass. The ratio of lactide/catalysator is one of key factors of successful ROP process to produce PLA with high molar mass. Kricheldorf and Weidner in a recent work investigated the effect of purity and ratio of lactide/catalysator and found that 
the application of neat stannous octoate resulting cyclic polylactides and not linear chains as assumed in previous decades. In addition, that was also observed at lower catalysator ratio higher molar mass could be achieved as well as higher catalysator rate causing lower molar mass [24]. In case of ROP produced PLLA sample this effect dominated that caused the measured low molar mass.

\section{Differential scanning calorimetry (DSC)}

Three samples were analyzed by DSC such as ROP produced PLLA, polycondensation produced PLLA and plasticized polycondensation produced PLLA. In case of sample which was produced by ROP method, the $\mathrm{Tg}$ was found at $34.6{ }^{\circ} \mathrm{C}$ (Fig. 7/1) which is under the $55-63{ }^{\circ} \mathrm{C}$ literary $\mathrm{Tg}$ range

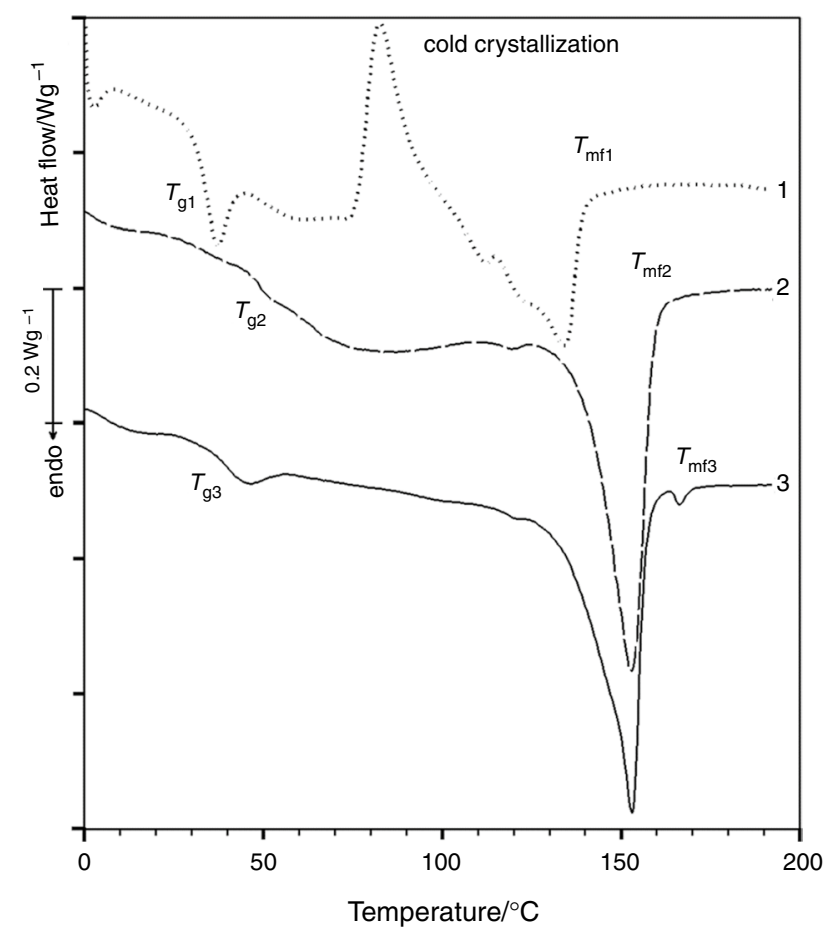

Fig. 7 DSC curves of 1. PLLA produced by ROP method; 2. PLLA produced by polycondensation method; 3 . plasticized version of PLLA produced by polycondensation method of PLLA [25-27]. Although the Mw of this sample was relatively low but the molecular chains were long enough to be crystallized during heating up of sample. This exothermal process was started at $76.4{ }^{\circ} \mathrm{C}$ and ended by onset temperature of decrystallization (melting) at $110.3^{\circ} \mathrm{C}$. The Tm highly depends on molar mass and ratio of crystal content. For example, in case of $\mathrm{Mw}=1.27 \times 10^{5} \mathrm{~g} \mathrm{~mol}^{-1}$, the $\mathrm{Tm}$ was found at $175.5^{\circ} \mathrm{C}$ for linear PLLA according to publication of Michalski and Lapienis [28]. Regarding the DSC curves of polycondensation produced reference sample with $\mathrm{Tg} 48.8^{\circ} \mathrm{C}$ (Fig. $7 / 2$ ) and its plasticized alternative with $\mathrm{Tg} 41.9^{\circ} \mathrm{C}$ (Fig. $7 / 3$ ), the $7{ }^{\circ} \mathrm{C}$ as decrease in $\mathrm{Tg}$ is obviously indicating that the plasticizer additive is compatible with the PLLA. The experienced drop of $\mathrm{Tg}$ is the direct consequence of plasticizer addition, as the plasticizer-getting into the space between the polymer chains-facilitates segmental motion of the polymer chains at lower temperature.

Although the molar mass of this material is low, but the plasticization of the material could be observed and validated by the measured drop of Tg. In case of both-reference and its plasticized alternative-materials, the absence of crystallization phases was caused by the slow cooling process of production because the thermal circumstances were appropriate for molecular chains to forming polymer crystals.

Based on the data of DSC measurements (Table 2) and the literature data of $100 \%$ crystalline PLA (the heat of melting is $93 \mathrm{~J} \mathrm{~g}^{-1}$ ) and with following the equation [29] below the crystallinity of samples could be calculated (1) and determined.

$K_{\%}=\frac{\Delta H_{\mathrm{m}}}{\Delta H_{\mathrm{c}}} \times 100$

$K_{\mathrm{i}(\%)}=\frac{H_{\mathrm{m}}-H_{\mathrm{c}}}{H_{\mathrm{lit}}} \times 100$

Initial crystallinity (2) could be calculated only in case of ROP-produced PLLA as this material could be crystallized during the heating. The ratio of initial crystallinity was calculated based on heats of crystallization and melting processes and found value as $6.3 \%$.
Table 2 Glass transition temperature, heat of crystallization, heat of melting and crystallinity of samples

\begin{tabular}{lllll}
\hline Material description & $\begin{array}{l}\text { Glass transition } \\
\text { temperature/ }{ }^{\circ} \mathrm{C}\end{array}$ & $\begin{array}{l}\text { Heat of } \\
\text { crystallization } / \mathrm{J} \mathrm{g}^{-1}\end{array}$ & $\begin{array}{l}\text { Heat of } \\
\text { melting/ } / \mathrm{g} \mathrm{g}^{-1}\end{array}$ & Crystallinity/\% \\
\hline PLLA $_{\text {produced by ROP }}$ & 34.6 & -19.79 & 25.63 & 27.6 \\
PLLA $_{\text {reference material }}$ & 48.8 & - & 40.38 & 43.4 \\
PLLA $_{\text {plasticized }}$ & 41.9 & - & 34.46 & 31.8 \\
\hline
\end{tabular}




\section{Conclusions}

The ring-opening polymerization process of poly(L-lactic) acid is a much more time-efficient polymerization method compared to the standard polycondensation. Although the ROP is more difficult process as it based on main steps such as dehydration/polymerization/depolymerization/ring-opening polymerization, this method could be resulted in higher molar mass than in case of polycondensation. During the polymerization type of the applied process temperatures and the type of the catalysator are key factors, defining the rate and efficiency of production. The temperatures of different phases can be optionally defined and adjusted. Over the obvious requirements of raw material and its properties (like melting, boiling and degradation temperatures) the process temperatures are mostly defined by experimental or production sized equipment and its abilities.

In case of lowering the temperature, the total time needs of process are getting higher for all steps. Although the application of higher temperature making the whole process be faster, but it is also endangering the entire polymerization. This problem is significant mainly at the lactide production phase, because if the temperature is running over the upper limit it may cause the material's partial or total degradation. The molar mass of sample was determined by GPC method. The resulted low molar mass is the direct consequence of type and relative high ratio of applied catalysator.

Over the ROP polymerization, in the second part of this study, the plasticization of PLLA was also investigated. Glycerol-dioleate as plasticizer was used plasticizing the previously prepared PLLA material. Based on the DSC analysis and the result as $7{ }^{\circ} \mathrm{C}$ of $\mathrm{Tg}$ drop, it was evaluated and verified the glycerol-dioleate is a compatible, i.e. primary plasticizer for PLLA.

Acknowledgements This research was supported by the European Union and the Hungarian State, co-financed by the European Regional Development Fund in the framework of the GINOP - 2.3.4.-15-201600004 project, aimed to promote the cooperation between the higher education and the industry.

Funding Open Access funding provided by University of Miskolc.

Open Access This article is licensed under a Creative Commons Attribution 4.0 International License, which permits use, sharing, adaptation, distribution and reproduction in any medium or format, as long as you give appropriate credit to the original author(s) and the source, provide a link to the Creative Commons licence, and indicate if changes were made. The images or other third party material in this article are included in the article's Creative Commons licence, unless indicated otherwise in a credit line to the material. If material is not included in the article's Creative Commons licence and your intended use is not permitted by statutory regulation or exceeds the permitted use, you will need to obtain permission directly from the copyright holder. To view a copy of this licence, visit http://creativecommons.org/licenses/by/4.0/.

\section{References}

1. Babu RP, O’Connor K, Seeram R. Current progress on bio-based polymers and their future trends. Prog Biomater. 2013. https://doi. org/10.1186/2194-0517-2-8.

2. Kim K, Lee B, Kim H. Thermal and mechanical properties of cassava and pineapple flours-filled PLA bio-composites. J Therm Anal Calorim. 2012. https://doi.org/10.1007/s10973-011-1350-y.

3. Arul Jeya Kumar A, Prakash M. Thermal properties of basalt/Cissus quadrangularis hybrid fiber reinforced polylactic acid biomedical composites. J Therm Anal Calorim. 2020. https ://doi.org/10.1007/s10973-019-09058-y.

4. Vidović E, Faraguna F, Jukić A. Influence of inorganic fillers on PLA crystallinity and thermal properties. J Therm Anal Calorim. 2017. https://doi.org/10.1007/s10973-016-5750-x.

5. Wang X, He W, Long L, Huang S, Qin S, Xu G. A phosphorusand nitrogen-containing DOPO derivative as flame retardant for polylactic acid (PLA). J Therm Anal Calorim. 2020. https://doi. org/10.1007/s10973-020-09688-7.

6. Díaz-Díaz AM, López-Beceiro J, Li Y, Cheng Y, Artiaga R. Crystallization kinetics of a commercial poly(lactic acid) based on characteristic crystallization time and optimal crystallization temperature. J Therm Anal Calorim. 2020. https://doi. org/10.1007/s10973-020-10081-7.

7. Day M, Nawaby AV, Liao X. A DSC study of the crystallization behaviour of polylactic acid and its nanocomposites. J Therm Anal Calorim. 2006. https://doi.org/10.1007/s1097 3-006-7717-9.

8. dos Santos Silva ID, Schäfer H, Jaques NG, et al. An investigation of PLA/Babassu cold crystallization kinetics. J Therm Anal Calorim. 2020. https://doi.org/10.1007/s10973-019-09062-2.

9. Refaa Z, Boutaous M, Xin S, Siginer DA. Thermophysical analysis and modeling of the crystallization and melting behavior of PLA with talc. J Therm Anal Calorim. 2017. https://doi. org/10.1007/s10973-016-5961-1.

10. Bouapao L, Tsuji H, Tashiro K, Zhang J, Hanesaka M. Crystallization, spherulite growth, and structure of blends of crystalline and amorphous poly(lactide)s. Polymer. 2007. https://doi. org/10.1016/j.polymer.2009.06.040.

11. Jasim A, Sunil K. Polylactide-chemistry, properties and green packaging technology: a review. Int J Food Prop. 2011. https:// doi.org/10.1080/10942910903125284.

12. Lee TS, Bee ST. Synthesis and production of poly(lactic acid). In: Lee TS, Bee ST, editors. Polylactic acid. 2nd ed. Amsterdam: Plastics Design Library; 2019. p. 53-95.

13. Mehta R, Kumar V, Bhunia H, Upadhay SN. Synthesis of poly(lactic acid): a review. J Macromol Sci, Phys. 2006. https:// doi.org/10.1080/15321790500304148.

14. Hu Y, Daoud WA, Cheuk KKL, Lin CSK. Newly developed techniques on polycondensation, ring-opening polymerization and polymer modification: focus on poly(lactic acid). Materials. 2016. https://doi.org/10.3390/ma9030133.

15. Stridsberg KM, Ryner M, Albertsson AC. Controlled ring-opening polymerization: polymers with designed macromolecular architecture. In: Albertsson AC, editor. Degradable aliphatic polyesters. Berlin: Springer; 2002. p. 41-65.

16. Zhang J, Krishnamachari P, Lou J, Shahbazi A. Synthesis of poly $(\mathrm{L}(+)$ lactic acid) by polycondensation method in solution. In: Uzochukwu G, Schimmel K, Chang SY, Kabadi V, LusterTeasley S, Reddy G, Nzewi E, editors. Proceedings of the 2007 national conference on environmental science and technology; 2007. p. 3-8.

17. Pholharn D, Srithep Y, Morris J. Effect of initiators on synthesis of poly(L-lactide) by ring opening polymerization. IOP 
Conf Ser Mater Sci Eng. 2017. https://doi.org/10.1088/1757899X/213/1/012022.

18. Pholharn D, Srithep Y, Morris J. Ring opening polymerization of poly(l-lactide) by macroinitiator. AIP Conf Proc. 2019. https://doi. org/10.1063/1.5088274.

19. Kaihara S, Matsumura S, Mikos AG, Fisher JP. Synthesis of poly(L-lactide) and polyglycolide by ring-opening polymerization. Nat Protoc. 2007. https://doi.org/10.1038/nprot.2007.391.

20. Wang C, Li H, Zhao X. Ring opening polymerization of L-lactide initiated by creatinine. Biomaterials. 2004. https://doi. org/10.1016/j.biomaterials.2004.01.030.

21. Grijpma DW, Pennings AJ. Polymerization temperature effects on the properties of L-lactide and $\varepsilon$-caprolactone copolymers. Polym Bull. 1991. https://doi.org/10.1007/BF00316903.

22. Icart LP, Fernandes E, Agüero L, Cuesta MZ, Silva DZ, Rodríguez-Fernández DE, Souza FG Jr, Limaa ML, Dias ML. End functionalization by ring opening polymerization: influence of reaction conditions on the synthesis of end functionalized poly(lactic acid). J Braz Chem Soc. 2018. https://doi.org/10.21577 /0103-5053.20170118.

23. Cuiffo M, Snyder J, Elliot A, Romero N, Kannan S, Halada G. Impact of the fused deposition (FDM) printing process on polylactic acid (PLA) chemistry and structure. Appl Sci. 2017. https ://doi.org/10.3390/app7060579.
24. Kricheldorf HR, Weidner SM. High molar mass cyclic poly(Llactide) obtained by means of neat tin(II) 2-ethylhexanoate. Polym Chem. 2020. https://doi.org/10.1039/D0PY00811G.

25. Spinu M, Jackson C, Keating MY, Gardner KH. Material design in poly(lactic acid) systems: block copolymers, star homo- and copolymers, and stereocomplexes. J Macromol Sci A. 1996. https ://doi.org/10.1080/10601329608014922.

26. Bigg DM. Polylactide copolymers: effect of copolymer ratio and end capping on their properties. Adv Polym Technol. 2005. https ://doi.org/10.1002/adv.20032.

27. Phuphuak Y, Chirachanchai S. Simple preparation of multibranched poly(L-lactic acid) and its role as nucleating agent for poly(lactic acid). Polymer. 2013. https://doi.org/10.1016/j.polym er.2012.11.070.

28. Michalski A, Lapienis G. Synthesis and characterization of highmolar-mass star-shaped poly(L-lactide)s. Polimery. 2018. https:// doi.org/10.14314/polimery.2018.7.2.

29. Nohara LB, Nohara EL, Moura A, Gonçalves JMRP, Costa ML, Rezende MC. Study of crystallization behavior of poly(phenylene sulfide). Polímeros. 2006. https://doi.org/10.1590/S0104-14282 006000200009 .

Publisher's Note Springer Nature remains neutral with regard to jurisdictional claims in published maps and institutional affiliations. 